sada, principalmente, pela ausência de-vegetação dominante ectotrófica, que favorece a atividade de fungos que decompõem a liteira a um tal grau que não há acumulação de uma camada significante de húmus fresco,

\section{BIBLIOGRAFIA CITADA}

Anderson, A. B.; Prance, G. T. \&

ALBUQUeRQue, B. W. P.

1975 - Estudos sobre a vegetaçăo das campinas amazônicas. II. Acta Amazonica, 5(3) : 225-242.

Batista, A. Chaves

1960 - Exposição sobre solos amazônicos. In : Simpósio sobre a Biota Amazônica, Belém. Exposição do IMUFPe (unpublished) cf Sin- ger, R. 1969, A. Chaves Batista. Sydowia, $22: 344$.

GADGIL, R. L. \& Gadgil, G. A.

1971 - Mycorrhiza and litter decomposition. Nature, $233: 113$.

Oláh, G. M.; Reisinger, O. \& Kilbertus, G. 1978 - Biodégradation et humification. Montreal.

SINGER, R.

1971 - Forest mycology and forest communities in South America. II. In: Hacskaylo, E. Mycorrhizae. Washington, U, S. Gov. Printing Office. p. 204-215.

Singer, R. \& Morello, J, H.

1960 - Ectotrophic tree mycorrhiza and forest communities. Ecology, 41: 549-551.

(Aceito para publicação em $08 / 06 / 78$ )

\title{
Nota prévia sobre o "pão do índio" da Amazônia Brasileira
}

\author{
Izonete de Jesus da Silva Araujo \\ Instituto Nacional de Pesquisos \\ da Amazônia, Manaus \\ Maria Alves de Sousa \\ Universidade Federal da Paraiba
}

O "pão do índio" é amplamente distribuído na Amazônia, onde encontra condições favoráveis ao seu desenvolvimento, chegando a atingir mais de $60 \mathrm{~kg}$ (Maravalhas, 1965). É subterrâneo, o que torna difícil sua coleta, sendo encontrado principalmente por leigos nas escavações para construções de estradas e arações para lavouras. Até o momento, temos registros de sua ocorrência nos Estados do Amazonas, Mato Grosso, Pará e Territórios de Rondônia e Roraima.

O organismo em estudo é um "milita" (grande esclerócio) que pertence ao gênero imperfeito, Pachyma Fries. O esclerócio é muito pesado, tuberoso, comestível. Segundo Maravalhas (1965), contém muito material de reserva, predominando polissacarídeos. É constituído por hifas que formam uma massa compacta, vítrea, opaca, muito dura quando seca, mucilaginosa em $\mathrm{KOH}$, e variegada de cores, correspondendo a Locquin (1975), mais ou menos "albus" (H8h) a "russus" (A2C) muito claro ou escuro. A região periférica é constituída por uma camada de hifas laxas de cor ho- mogênea, "pudorinus" (Q5h), sobre a qual forma-se uma crusta delgada, "venetus" (Z1b) escuro e quebradiça (Fig. 1). O sistema hifal é dimítico com hifas geradoras e esqueléticas. Hifas geradoras com $3-7 \mu \mathrm{m}$ de diâmetro, hialinas, de paredes delgadas, às vezes levemente espessadas, com fíbulas, septos não muito freqüentes, não ramificadas ou ramificadas. Quando ramificadas apresentam uma ramificação longa ou várias ramificações curtas. Algumas hifas, apresentam pequenas $\mathrm{e}$ abundantes granulações, que coram intensamente em azul de algodão. Hifas esqueléticas medindo $4,2-15 \mu \mathrm{m}$ de diâmetro, hialinas, de paredes espessadas, ápices obtusos, septos e ramificações não observados. Estas hifas quando observadas em $\mathrm{KOH}$ apresentam as paredes mais nitidamente visíveis e as extremidades agudas e freqüentemente curvas.

Os basidiocarpos analisados foram obtidos em laboratório, sob a orientação do Dr. Rolf Singer, o qual colocou um esclerócio num balde galvanizado com solo humoso conservado umedecido. Após 2 meses observamos, 


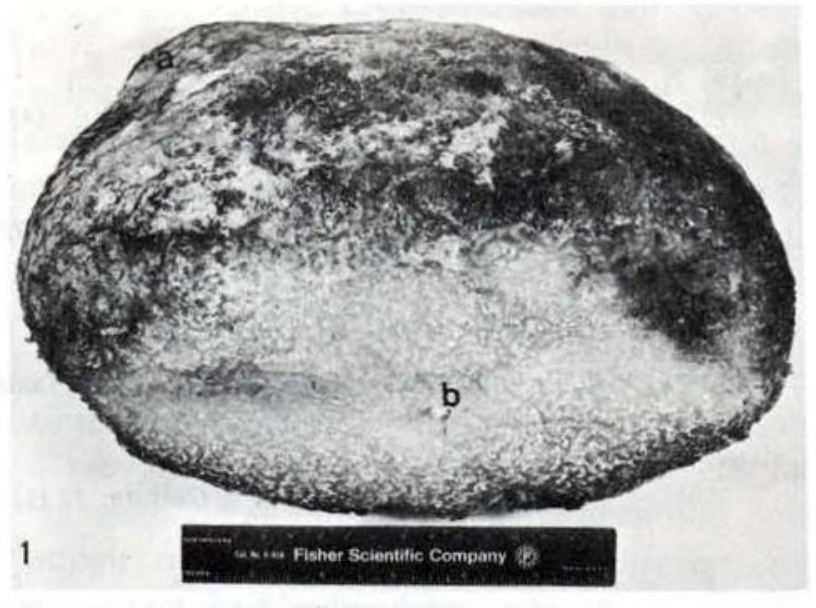

Fig. 1 - Detalhes macroscópicos do esclerócio do pão do índio da Amazônia : a. crusta quebradiça mostrando a regiāo periférica de cor mais clara: b. massa interna variegada

inicialmente, pequenas protuberâncias mais ou menos globosas, conglutinadas ou $0,4-2$ $\mathrm{cm}$ distanciadas que, ao se alongarem as partes apicais, se tornaram mais volumosas, determinando conseqüentemente a concrescência de todos os corpos frutíferos. Estes produziram um himenóforo poróide com himênio fértil em toda superfície inferior do píleo. Os basidiocarpos são carnosos, de forma irregular, chegando até $5,5 \mathrm{~cm}$ de comprimento. A região sunerior, compreenclendo $4 \mathrm{~mm}$ de espessura, é estéril, com superfície convexa de cor "aurantius" (S4h), "pudorinus" (Q6h) com a idade, azonada, glabra e sem escamas. A região inferior atenua-se gradativamente para a base, com $1-4$ poros por $\mathrm{mm}$, circulares a alongados, medindo $115-416 \times 92-175$ $\mu \mathrm{m}$ e dissepimento inteiro, obtuso, glabro, medindo $66-222 \mu \mathrm{m}$ de espessura (Figs. 2 e 3 ) O sistema hifal é monomítico, constituído por hifas geradoras de paredes delgadas, hialinas, com fíbulas e septos, ramificadas ou não, medindo $2,8-5,9 \mu \mathrm{m}$ de diâmetro; algumas possuem granulações que coram intensamente em azul de algodão. Basídios clavados com $16,8-22,4 \times 5,5-6,7 \mu \mathrm{m}$. Basidiósporos hialinos, lisos, apiculados, aproximadamente cilindricos, medindo $5,6-7 \times 2,8-3,9 \mu \mathrm{m}$.

O material em estudo apresenta algumas características macro e microscópicas dife- rentes dos outros Poliporáceos que produzem esclerócio típiço do gênero Pachyma. Comparando com a descrição dada por Engler (1900), Brade (1930) e Gonçalves (1937) para Polyporus sapurema Möller, material coletado no sul do Brasil, vimos que o nosso difere, principalmente, na forma e tamanho do píleo e dos basidiósporos, na falta de zonação, pêlos, escamas e estipe central aveludado (o espécimem da Amazônia é praticamente séssil). Também difere de Pleurotus tube-regium porque este apresenta lamelas e produz basidiocarpos maduros em uma semana sob condições semelhantes (Oso, 1977), bem como esclerócios e basidiocarpos dimíticos. O "tuckahoe", Poria cocos (Wolf, 1922 in Weber, 1929), que também produz um milita ou pachyma muito semelhante ao "pão do índio", cha-
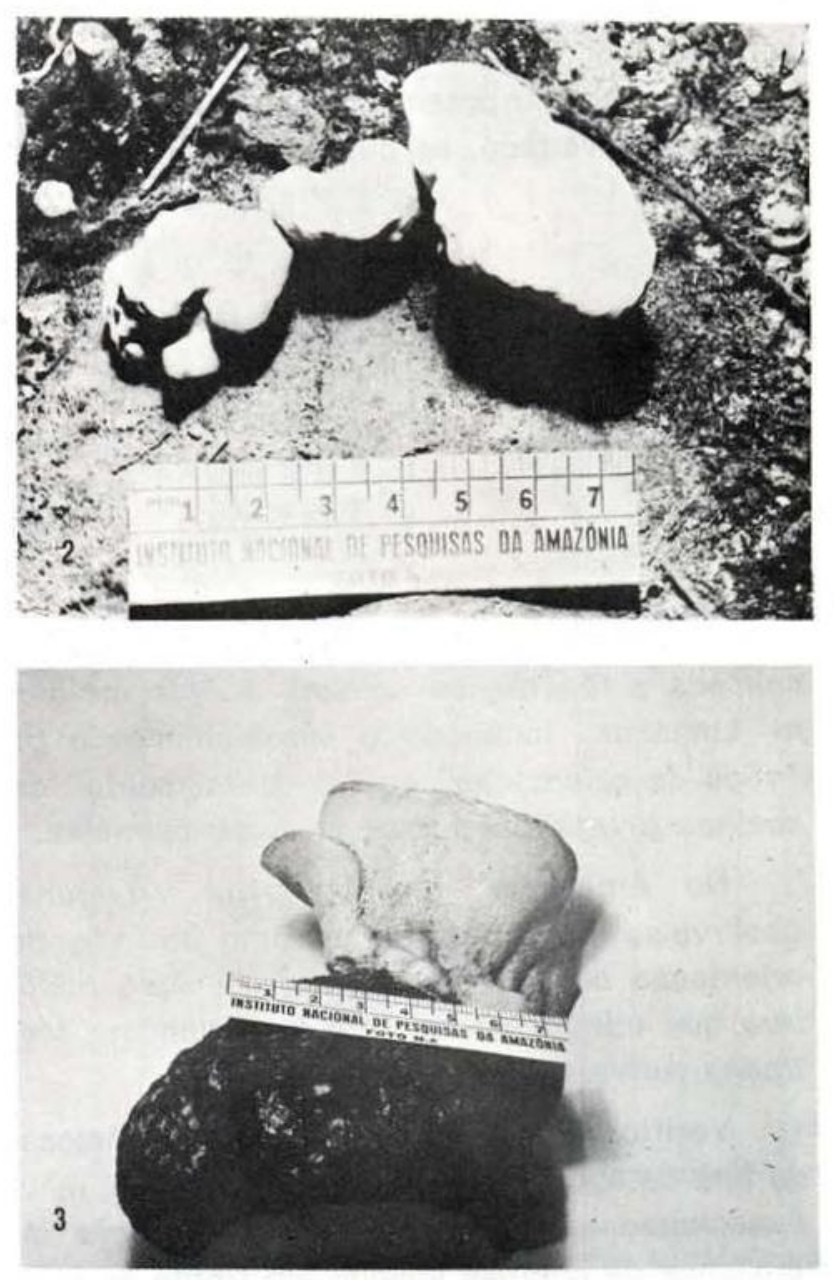

Figs. 2-3 - Caracteres macroscópicos do basidiocarpo:

2. forma jovem mostrando aspecto e disposiçăo inicial no esclerócio; 3. aspecto geral da forma adulta. 
mado "Indian bread", é diferente do nosso porque germina em laboratório produzindo basidiocarpo ressupinado. Na Austrália, e provavelmente na India e China, ocorrem também pachymas que produzem frutificações poliporóides férteis, como por exemplo, Polyporus mylitta, espécie austraiiana, chamada "black fellow's bread" ou "native bread".

Tudo indica que todos estes fungos são relacionados e que o nosso "pão do índio" da Amazônia é uma espécie nova. Investigações adicionais são necessárias para verificar se todos eles têm a anatomia suficientemente semelhante para reuní-los em um só gênero (Pachyma). Para um estudo comparativo, torna-se necessária a obtenção dos respectivos tipos ou materiais autênticos. Nossas investigações serão concluídas neste sentido, não somente por seu interesse taxonômico como também, por seu potencial econômico, que pode ser aproveitado, se cultivado.

\section{BIBLIOGRAFIA CITADA}

BRADE, A. C.

1930 - A saporema. Bol. Mus. Nac., 6 (4): 303-juj.

ENGler, A. \& Pranth, K.

1900 - Die Natürlichen Pflanzenfamilien, 1: 171-172.

GONÇALVES, R. D.

1937 - Saporema. O Biológico, 3 (10) : 302-306.

LoCQuin, M. V.

1975 - Guide des couleurs naturelles. De Taxia Fungorum.

Maravalhas, $\mathrm{N}$.

1965 - O pão de indio. Ciência e Cultura, 17 (1) : 18-20.

Oso, B. A

1977 - Pleurotus tuber-regium from Nigeria. Mycologia, $69(2)$ : 271-279.

Weber, G. F.

1929 - The ocurrence of Tuckahoes ant Poria cocos in Florida. Mycologia, 21(3) : 113-130.

WoLF, F. A.

1922 - The fruiting stage of the tuckahoe Pachyma cocoa. Jour. Elisha Mitchell Soc., 38: 127-137, apud Weber, G. F. - The ocurrence of Tuckahoes and Poria cocos in Florida. Mycologia. 21 (3) : 113-130.

(Aceito para publicação em 03/06/78)

\section{Baile em abelhas amazônicas}

V. de Portugal-Araújo

Instituto Nacional de Pesquisas

da Amazônia, Manaus
A designação de "baile das abelhas" é aplicada a fenômenos comuns a Apis mellifera Linnaeus, incluindo o acasalamento e os "vôos de orientação" ou "de treinamento" de abelhas jovens em frente às suas colmeias.

No Amazonas, em Melipona e Trigona, observa-se um fenômeno próximo do "vôo de orientação ou de treinamento" de Apis mellifera que atinge um aspecto incomum em Melipona rufiventris cf. paraensis Ducke.

Verifica-se entre as abelhas amazônicas, de fins de agosto a princípios de outubro, mais especialmente em setembro, a formação de enxames de abelhas voando em frente às suas colmeias ou troncos povoados, geralmente ao meio do dia, podendo verificar-se mais tarde, mesmo que o tempo se apresente instável.
Sem qualquer sinal aparente de que o fenômeno se vai desencandear, inicia-se a saída ininterrupta de, possivelmente, todas as abeIhas adultas, incluindo abelhas jovens, que ficam voando em frente à colmeia ou tronco, num movimento suspenso, ascendente ou descendente, corpo inclinado de 20 a 40 graus e patas posteriores e médias estendidas para baixo. (Fig. 1).

Em rufiventris o número de abelhas pode atingir, aproximadamente, 5.000, formando, se o tempo se apresentar sem vento, um elipsóide de, aproximadamente, dois metros de altura por um metro e meio de diâmetro, de contornos perfeitos e completamente limitados, onde, na parte central vertical, as abelhas sobem lentamennte, descendo pela periferia ao 